\title{
Quantitative assessment of late gadolinium-enhancement in cardiac magnetic resonance predicts left ventricular remodeling in acute myocarditis
} Julien Jeanneteau*1, Loic Biere ${ }^{1}$, Fabrice Prunier ${ }^{1}$, Serge Villoteau ${ }^{2}$ and Alain Furber ${ }^{1}$

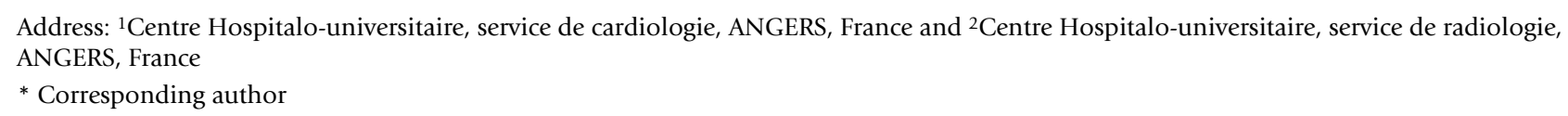

* Corresponding author

from 13th Annual SCMR Scientific Sessions

Phoenix, AZ, USA. 21-24 January 2010

Published: 21 January 2010

Journal of Cardiovascular Magnetic Resonance 2010, I2(Suppl I):O53 doi:I0.I I86/I532-429X-I2-SI-O53

This abstract is available from: http://jcmr-online.com/content/I2/SI/O53

(C) 2010 Jeanneteau et al; licensee BioMed Central Ltd.

\section{Purpose}

Cardiac magnetic resonance (CMR) is a major tool for the diagnosis of acute myocarditis. CMR allows myocardial inflammation visualization, especially with the T2 weighted and the late gadolinium enhancement (LGE) sequences. The aim of our study was to assess the value of LGE quantification to predict left ventricular (LV) remodeling.

\section{Methods and results}

We screened 33 consecutive patients hospitalized with the clinical diagnosis of acute myocarditis. CMR with delayed-enhancement sequences was performed during the acute phase and at 3 months for 21 patients. LGE mass (in the acute phase) was measured and compared to left ventricular ejection fraction (EF), LV mass, LV end-diastolic volume and LV end-systolic volume, in the acute episode and at 3 months.

During the acute phase, LGE was present in 18 patients (90.5\%). LGE mass significantly decrease at 3 months. EF significantly improves between the acute phase and 3 months later $(52 \pm 11.7 \%$ vs. $59.5 \pm 9.1 \%, \mathrm{p}<0.01)$. There was an inverse correlation between LGE mass in the acute phase and EF at 3 months $(r=-0.44, \mathrm{p}=0.044)$. The LGE mass in the acute phase was correlated with LV EDV $(\mathrm{r}=$ $0.62, \mathrm{p}=0.003)$ and LV ESV at 3 months $(\mathrm{r}=0.76, \mathrm{p}<$ $0.001)$. LGE mass decrease was significantly correlated with the improvement of EF between the acute phase and 3 months $(\mathrm{r}=-0.82, \mathrm{p}<0.001)$.

\section{Conclusion}

LGE quantification in the acute phase of myocarditis may predict LV remodeling. 